\title{
How to Apply Transobturator and Transvaginal Tape Needles: A Cadaveric Demonstration Study with Anatomical Landmarks
}

(D) Illker SELÇUKa,

(D) Illkan TATAR

(D) Emre HURic

aDepartment of Gynecologic Oncology, Health Sciences University,

Zekai Tahir Burak Woman's Health Practice and Research Center,

Departments of

${ }^{\mathrm{b} A n a t o m y,}$

Urology,

Hacettepe University Faculty of Medicine,

Ankara, TURKEY

Received: 10.09.2018

Received in revised form: 15.10 .2018

Accepted: 16.10 .2018

\section{Correspondence:}

İlker SELÇUK

Health Sciences University,

Zekai Tahir Burak Woman's Health Practice and Research Center,

Department of Gynecologic Oncology,

Ankara, TURKEY

ilkerselcukmd@hotmail.com

\begin{abstract}
Objective: This study aimed to demonstrate a proper method of performing transobturator tape (TOT) and transvaginal tape (TVT) needle (trocar) insertion with anatomical landmarks on a cadaver. Material and Methods: In April 2017, at Prof. Rhoton Anatomy Laboratory, Bahcesehir University, Istanbul/Turkey, the cadaveric workshop of Pelvic Reconstructive and Functional Urology Surgery, an advanced masterclass on anatomy and surgery using fresh frozen cadavers was held. During the course, transobturator tape (TOT, outside-in method) and transvaginal tape (TVT, bottom-to-top method) procedures were performed on a cadaveric model with a detailed dissection of anatomical landmarks. Results: After passing the skin, TOT needle passes just beneath the adductor longus tendon and through the gracilis tendon, adductor brevis tendon, obturator externus muscle, obturator membrane, obturator internus muscle, and endopelvic fascia, so comes out from the vaginal incision. During this course, there was a risk of injury to the obturator nerve. The average distance of TOT needle to the obturator nerve was found $1.9 \mathrm{~cm}$. However, for the TVT operation, the risk of vascular, bowel, or bladder injury was higher than the TOT operation because of the retropubic pathway. The average distance of TVT needle to the obturator neurovascular bundle at the retropubic space was found $3.4 \mathrm{~cm}$. Conclusion: Performing the TOT and TVT needle insertions properly with correct hand movements and anatomical knowledge of neighbouring structures will decrease the risk of complications.
\end{abstract}

Keywords: Anatomy; cadaver; suburethral slings; stress urinary incontinence; education he involuntary leakage of urine during coughing, sneezing, or exercise (conditions that increase intra-abdominal pressure) is called stress urinary incontinence (SUI). It is the most common type of urinary incontinence and $10 \%$ to $30 \%$ of women are affected from the symptoms related to SUI. ${ }^{1,2}$ Although conservative approaches such as bladder training and pelvic floor muscle therapy have been used for the management of SUI; to improve the quality of life, surgical treatment is highly emerging for many women who are suffering from SUI during their social life. $^{3}$

Despite the low-risk profile of conservative management, frequently they result in modest benefits. Women under 55 years of age who have higher educational levels and severe incontinence symptoms generally choose a surgical intervention to solve this problem. ${ }^{4}$ Since the 1990 s tension free mid-urethral slings, transobturator tape (TOT) and transvaginal tape (TVT) procedures, are commonly encountered during the surgical management of SUI. ${ }^{5}$ The main aim of these procedures is to place a mesh just beneath the mid-urethra such that it causes an inflammation in a tensionfree way and shapes a hammock to prevent urethral failure during the increase of intra-abdominal pressure. Both TOT and TVT operations are highly effective in the management of SUI with satisfactory success rates, 
approximately $80 \%$, and they provide similar quality of life after surgery despite different types of adverse events. ${ }^{6}$ Mid-urethral slings, either retropubic (TVT) or transobturator (TOT) approach, are now the standard surgical management of SUI and TOT operation is commonly the first choice for uncomplicated cases. ${ }^{7}$ This study demonstrates the proper surgical steps of TOT and TVT needle insertion on a cadaveric model with discussion of neighbouring anatomical structures and potential complications.

\section{MATERIAL AND METHODS}

In April 2017, at Prof. Rhoton Anatomy Laboratory, Bahcesehir University, Istanbul/Turkey; a cadaveric workshop of Pelvic Reconstructive and Functional Urology Surgery, an advanced masterclass on anatomy and surgery using fresh frozen cadavers, was held in collaboration with International School of Urologic Surgery. All the urogynecologic procedures were performed by a total of 15 participants under mentorship. In this study, we showed proper needle insertions for TOT and TVT procedures on a cadaveric model according to anatomical landmarks. There is no need of Ethics Committee Approval.

\section{REGIONAL ANATOMY}

The obturator foramen, which is formed between the pubic bone and ischium, connects the pelvis to the thigh. Obturator membrane, a tiny soft membranous tissue, covers the obturator foramen and at the superior part of the foramen a hole surrounded by the obturator membrane forms the obturator canal where obturator vessels and nerve pass. After passing the obturator canal to the direction of thigh, obturator artery shapes a circle with its anterior and posterior branch, whereas the obturator nerve lies at the middle part of the foramen with its anterior (superficial) and posterior (deeper) branch, however there is a wide range of variety in the course of these anatomical structures (Figure 1). Gracilis muscle forms the superficial layer muscle of the medial thigh muscles that originates from the body of pubic bone and inferior pubic ramus (external part), inferior to it adductor longus muscle is noticed that originates from the body of pubic bone under the pubic tubercle and deep to it adductor brevis muscle is noticed that originates from the body of pubic bone and inferior pubic ramus (internal part) (Figure 1). Finally, the external part of the obturator membrane is surrounded by the obturator externus muscle under the adductor brevis muscle and inside the obturator membrane the obturator internus muscle is identified.

The covering fascia of the levator ani muscle is called pelvic diaphragm and the superior aspect of it attaches to the posterior part of the body of pubic bone (retropubic space), attaches with the obturator fascia and lies posteriorly to the fascia over the priformis muscle and anterior sacrococcygeal ligament. This fascia covering the deeper part of pelvic organs and their attachments to the lateral pelvic wall is called endopelvic fascia. The base of the bladder and the urethra are supported by the endopelvic fascia. ${ }^{8,9}$

\section{RESULTS}

\section{TRANSOBTURATOR TAPE SURGERY (OUTSIDE-IN METHOD)}

Both TOT and TVT procedures were performed in dorsal-lithotomy position; hips were slightly hyperflexed (buttocks are 90-120 degrees away from the operation table) and legs were in moderate abduction (30-60 degrees lateral from the midline)

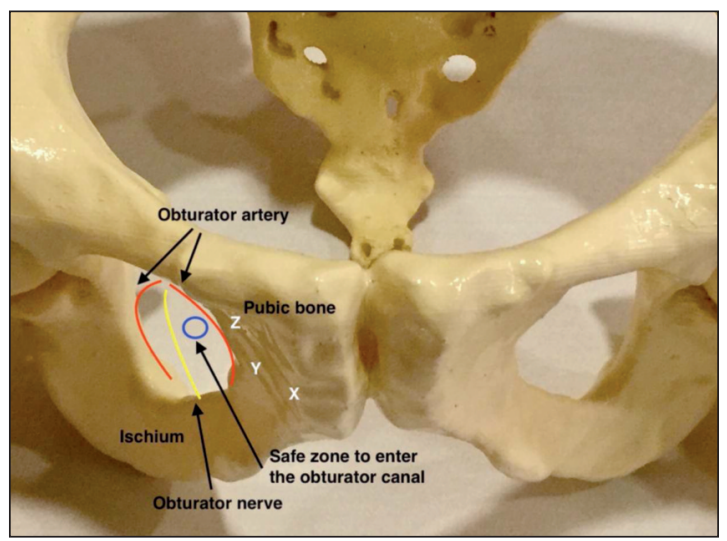

FIGURE 1: Obturator canal, obturator artery and nerve; safe zone to enter the obturator canal.

$\mathrm{X}$ : Origin of Gracilis muscle tendon; Y: Origin of Adductor brevis muscle tendon; Z: Origin of Adductor longus muscle tendon. 
with external rotation, and $16 \mathrm{~F}$ foley catheter was inserted into the bladder with the aim of revealing the urethra.

A mid-urethral anterior vaginal wall incision was performed $1-1.5 \mathrm{~cm}$ inferior to the external urethral meatus and $1.5-2 \mathrm{~cm}$ in length. Vagina was cut in full-thickness and vaginal flap that is anterior to the periurethral fibroadipose tissue was dissected towards the obturator membrane. The index finger was also used for blunt dissection from the level of inferior pubic ramus. The details of the TOT needle insertion (right side) are described in Figure 2a-j.
During transobturator tape surgery, after passing the skin the TOT needle passes through the gracilis tendon, adductor brevis tendon (just beneath the adductor longus tendon), obturator externus muscle, obturator membrane, obturator internus muscle, and endopelvic fascia, so comes out from the vaginal incision. When the patient is in dorsal-lithotomy position, the posterior branch of the obturator nerve becomes closer to the ischiopubic ramus (the intersection point of inferior pubic ramus and inferior ramus of the ischium) and TOT needle during its course. The average distance
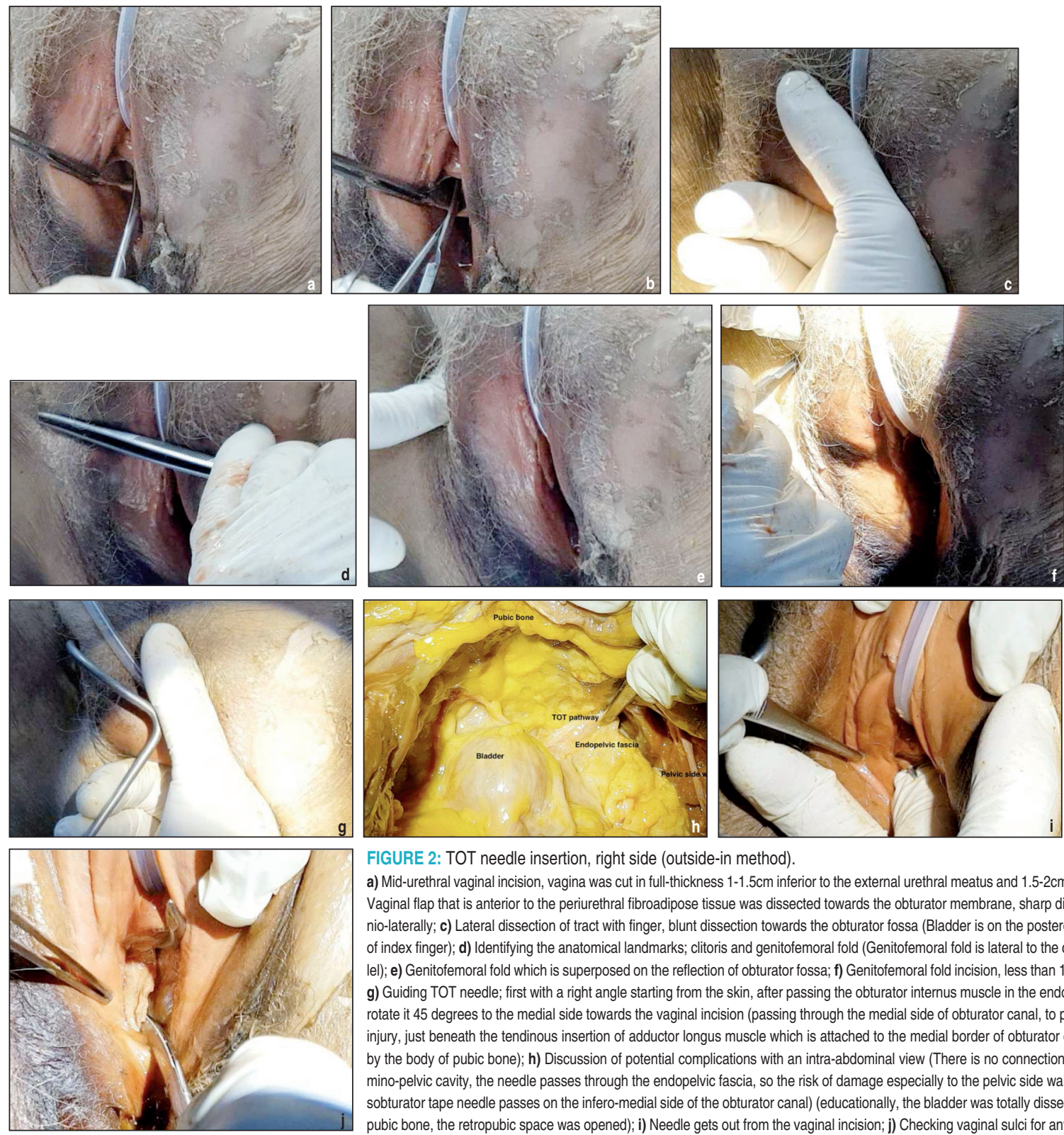

FIGURE 2: TOT needle insertion, right side (outside-in method).

a) Mid-urethral vaginal incision, vagina was cut in full-thickness $1-1.5 \mathrm{~cm}$ inferior to the external urethral meatus and $1.5-2 \mathrm{~cm}$ in length; $\mathbf{b}$ ) Vaginal flap that is anterior to the periurethral fibroadipose tissue was dissected towards the obturator membrane, sharp dissection cranio-laterally; c) Lateral dissection of tract with finger, blunt dissection towards the obturator fossa (Bladder is on the postero-medial part of index finger); d) Identifying the anatomical landmarks; clitoris and genitofemoral fold (Genitofemoral fold is lateral to the clitoris, parallel); e) Genitofemoral fold which is superposed on the reflection of obturator fossa; f) Genitofemoral fold incision, less than $1 \mathrm{~cm}$ in length; g) Guiding TOT needle; first with a right angle starting from the skin, after passing the obturator internus muscle in the endopelvic fascia rotate it 45 degrees to the medial side towards the vaginal incision (passing through the medial side of obturator canal, to prevent nerve injury, just beneath the tendinous insertion of adductor longus muscle which is attached to the medial border of obturator canal formed by the body of pubic bone); $h$ ) Discussion of potential complications with an intra-abdominal view (There is no connection to the abdomino-pelvic cavity, the needle passes through the endopelvic fascia, so the risk of damage especially to the pelvic side wall is low, transobturator tape needle passes on the infero-medial side of the obturator canal) (educationally, the bladder was totally dissected from the pubic bone, the retropubic space was opened); i) Needle gets out from the vaginal incision; j) Checking vaginal sulci for any perforation. 
of the obturator nerve (posterior branch) to the TOT needle was $1.9 \mathrm{~cm}$. The distance between the posterior branch of obturator nerve and TOT needle is demonstrated in Table 1.

\section{TRANSVAGINAL TAPE SURGERY (BOTTOM-TO-TOP METHOD)}

Similar to the TOT procedure, a mid-urethral anterior vaginal wall incision was performed $1-1.5 \mathrm{~cm}$ inferior to the external urethral meatus and 1.5-2 $\mathrm{cm}$ in length. Vagina was cut in full-thickness and vaginal flap that is anterior to the periurethral fibroadipose tissue was dissected towards the retropubic space behind the pubic symphysis. During this step the urethra and the bladder were deviated to the opposite side of needle by inserting a foley catheter (a rigid catheter could also be beneficial) to the urethra. The details of the TVT needle insertion (right side) are described in Figure 3a-g.

During transvaginal tape surgery, the TVT needle is hold by the non-dominant hand just posterior to the anterior vaginal wall and lateral to the mid-urethra. A rigid bladder catheter will protect the urethra and bladder from an injury. After getting into endopelvic fascia, the needle passes just posterior to the pubic bone at the retropubic space. During this step; while pushing the needle towards the suprapubic exit points, it is extremely important to draw down the elbow that allows the needle to be as closer as possible to the pubic bone. The average distance of TVT needle to the obturator neurovascular bundle was $3.4 \mathrm{~cm}$. The distance between the obturator canal and TVT needle is demonstrated in Table 1.

\section{DISCUSSION}

Both TOT and TVT operations provide highly successful results for the management of SUI with different complication types. However, performing the proper steps of TOT and TVT needle insertions during these surgical procedures will decrease the potential complications. This study showed how to apply the TOT and TVT needles with a pictorial demonstration on a cadaver.

Totally, three cadavers were dissected to understand the anatomical landmarks. During TOT surgery, the risk of neural damage is slightly higher because of the close proximity of the obturator nerve. We found an average distance of $1.9 \mathrm{~cm}$ between the obturator nerve and TOT needle. In the literature, Whiteside and Walters found this distance $2.8 \mathrm{~cm}$ and Spinosa et al. identified a $2.7 \mathrm{~cm}$ distance for this relation. ${ }^{10,11}$ On the other hand, Hinoul et al. described a $0.7 \mathrm{~cm}$ distance which is very close. ${ }^{12}$ Bonnet et al. suggested that TOT surgery is a safe and reproducible method, irrespective of surgeon's experience based on the uniform path of TOT needle and they found this distance with a median of $2.5 \mathrm{~cm} .{ }^{13}$ Inserting the TOT needle as possible as medially, close the ischiopubic ramus will also decrease the risk of obturator nerve injury. Although the nerve damage causes a deficiency in adduction, an injury to arterial or venous structures causes a hematoma in the retropubic or obturator area, mostly arising from the injuries of small branches derived from the anterior branch of obturator artery that lies close to the ischiopubic ramus where the TOT needle passes. ${ }^{14}$ Mickey M. Karram defined the distance of obturator artery to the TOT needle as $1.1 \mathrm{~cm} .{ }^{15} \mathrm{We}$ agree on the consistent path of TOT needle during the surgery that it passes through the gracilis muscle tendon, adductor brevis muscle tendon and obturator externus muscle. Moreover, the TOT needle does not pass through the adductor longus muscle tendon because its attachment stays superiorly to the TOT needle insertion point on the skin where is parallel to the clitoris at the genitofemoral fold. Hyperflexion of hips with an angle of 90-120 degrees from the operation table and moderate abduction

TABLE 1: The distance between the obturator nerve and TOT needle, and obturator neurovascular bundle and TVT needle.

\begin{tabular}{|lccc|}
\hline & Cadaver 1 & Cadaver 2 & Cadaver 3 \\
\hline Distance to obturator nerve during TOT surgery & $2.2 \mathrm{~cm}$ & $1.5 \mathrm{~cm}$ & $2 \mathrm{~cm}$ \\
\hline Distance to obturator neurovascular bundle during TVT surgery & $3.9 \mathrm{~cm}$ & $3.1 \mathrm{~cm}$ & $3.2 \mathrm{~cm}$ \\
\hline
\end{tabular}



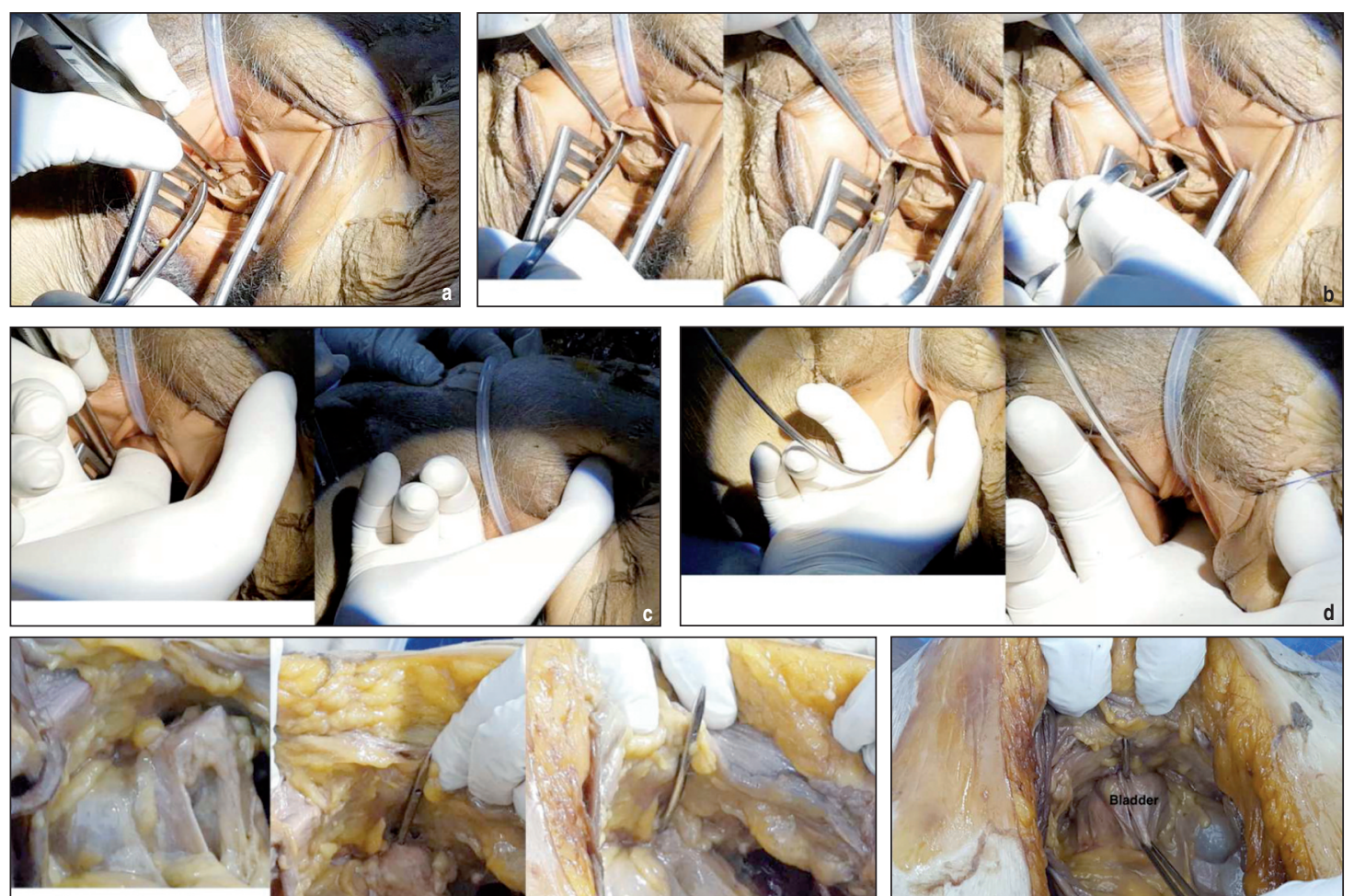

Wrong, not beneath the pubic bone
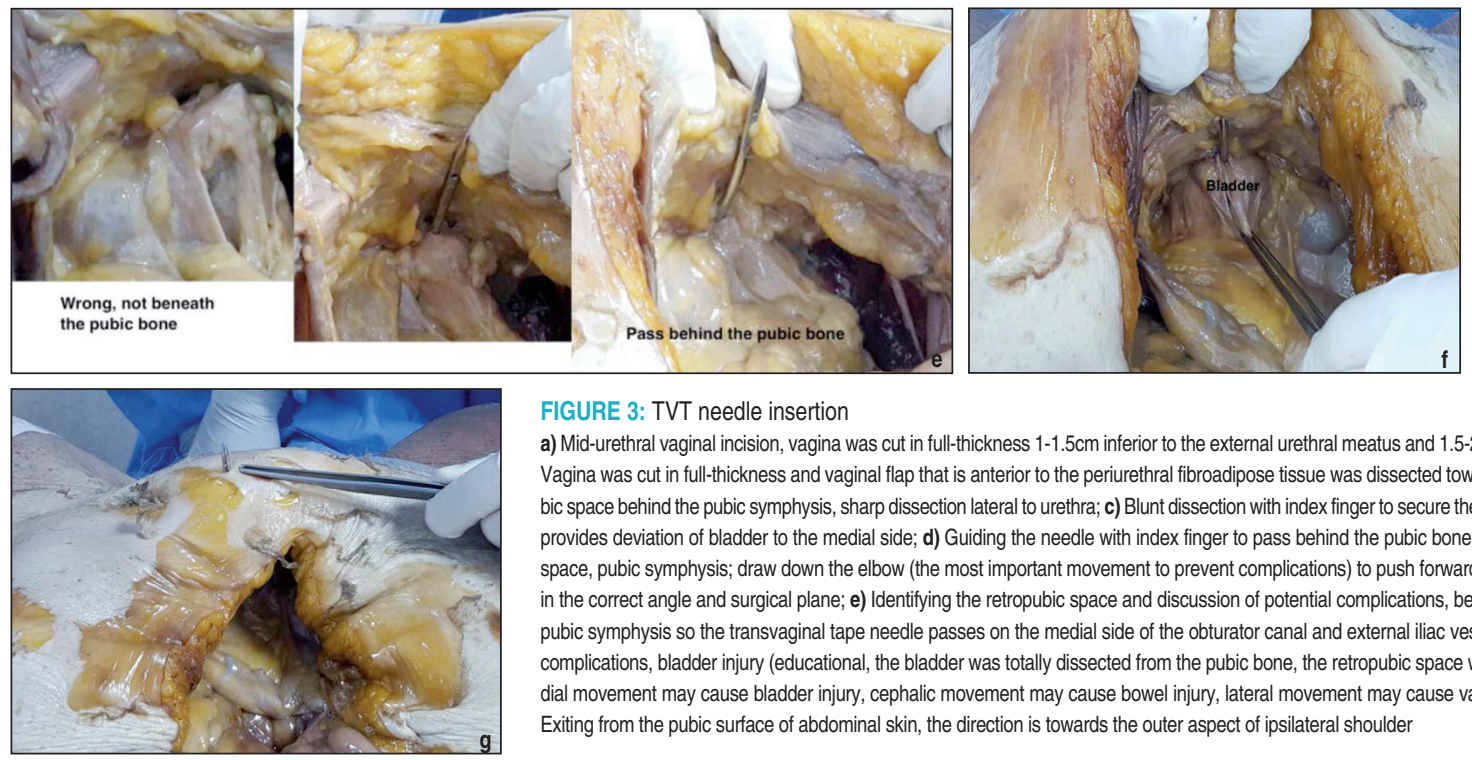

FIGURE 3: TVT needle insertion

a) Mid-urethral vaginal incision, vagina was cut in full-thickness $1-1.5 \mathrm{~cm}$ inferior to the external urethral meatus and $1.5-2 \mathrm{~cm}$ in length; b) Vagina was cut in full-thickness and vaginal flap that is anterior to the periurethral fibroadipose tissue was dissected towards the retropubic space behind the pubic symphysis, sharp dissection lateral to urethra; $c$ ) Blunt dissection with index finger to secure the anatomic plans, provides deviation of bladder to the medial side; d) Guiding the needle with index finger to pass behind the pubic bone at the retropubic space, pubic symphysis; draw down the elbow (the most important movement to prevent complications) to push forward the TVT needle in the correct angle and surgical plane; e) Identifying the retropubic space and discussion of potential complications, be just beneath the pubic symphysis so the transvaginal tape needle passes on the medial side of the obturator canal and external iliac vessels; f) Learning complications, bladder injury (educational, the bladder was totally dissected from the pubic bone, the retropubic space was opened; medial movement may cause bladder injury, cephalic movement may cause bowel injury, lateral movement may cause vascular injury); g) Exiting from the pubic surface of abdominal skin, the direction is towards the outer aspect of ipsilateral shoulder

with an angle of 30-60 degrees from the midline will increase the distance between the TOT needle and obturator nerve. In this manner, correct patient positioning is extremely important to perform a proper TOT needle insertion with less risk of obturator nerve injury however, the additional benefit of Trendelenburg position should also be evaluated. ${ }^{12}$

During TVT operation, we noted a higher risk of injury to the bladder and small bowels, however damage to the laterally lying vessel structures was not easy that the average distance of the obturator neurovascular bundle to the TVT needle was $3.4 \mathrm{~cm}$. Jaburek et al. found an average distance of $3.6 \mathrm{~cm}$ to the obturator vessels during retropubic surgery. ${ }^{16}$
Corona mortis which is a vascular anastomosis between the external iliac or epigastric vessels and obturator vasculature has the risk of injury during blind maneuvers. ${ }^{17}$ We identified an additional $1 \mathrm{~cm}$ length for the risk of corona mortis injury during this procedure. Mickey M. Karram defined the distance between the TVT needle and obturator neurovascular bundle as $3.2 \mathrm{~cm}$ and corona mortis as 3.9 $\mathrm{cm}$ at the retropubic space. ${ }^{15}$ Excessive lateral deviation of the TVT needle may increase the risk of vessel injury, nevertheless holding the TVT needle in the longitudinal axis and feeling the posterior aspect of pubic bone during the movement of TVT needle will decrease the risk of adverse events. During this step, drawing down the elbow allows the needle to 
stay in maximal closeness to the pubic bone at the retropubic space. As described by Bonnet et al., we noticed that bot TOT and TVT procedures are performed in the endopelvic fascia and have no relation with the pelvic cavity, additionally the levator ani muscle is not perforated. ${ }^{13}$

\section{EFFICACY AND COMPLICATIONS OF TOT AND TVT PROCEDURES}

Despite a slightly higher rate of success, TVT operations are associated with much more complications; vascular injury (excess lateral movement of needle will damage external iliac or obturator vessels), bowel injury (excess cephalic movement of needle particularly damages small intestines), or bladder (excess medial movement of needle) injury. ${ }^{18} \mathrm{~A}$ large retrospective cohort study, consisting of 92,246 women, measuring the outcomes of mesh surgery for SUI $(56,648$ TVT and 34,704 TOT) in England between April 2007 and March 2015 revealed that periprocedural and 30-day complication rates for TVT and TOT were 2.4\% (2.3$2.5 \%)$ and $1.7 \%$ (1.6-1.8\%), respectively. After a mean follow-up of 4.2 years, the re-admission rate of at least once for TVT and TOT groups was 5.4\% and $4.9 \%$, respectively. ${ }^{19}$ Despite similar rates of intraoperative urethral injury, postoperative erosion, and de-novo overactive bladder; during TVT procedure the risk of bladder injury during surgery (60/1482 [TVT] vs. 5/1479 [TOT]; odds ratio [OR] $6.44,95 \%$ confidence interval [CI] 3.32-12.50) and postoperative urinary retention (48/1160 [TVT] vs. 24/1159 [TOT]; OR 1.93, 95\% CI 1.26-3.12) were considerably higher, whereas a lower rate of prolonged postoperative pain (24/1156 [TVT] vs. 69/1149 [TOT]; OR 0.36, 95\% CI 0.23-0.56) with the TVT procedure was observed in a recent systematic review and meta-analysis. ${ }^{20}$ Tommaselli et al. analyzed the current literature regarding medium- and long-term outcomes and complications of TVT and TOT procedures; urinary tract infections ( $10.1 \%$ vs. $3.6 \%$; OR $3.29,95 \%$ CI 2.07-5.28, $\mathrm{p}<0.001)$ and bladder or urethral perforations $(2.5 \%$ vs. $0.4 \%$; OR $7.01,95 \%$ CI $2.94-$ 17.90, $\mathrm{p}<0.001)$ were more common in the TVT procedure, whereas vaginal injuries ( $3.3 \%$ vs. $0.4 \%$;
OR 7.96, 95\% CI 1.15-157.9, $\mathrm{p}=0.02$ ) and pain (5.9\% vs. $1.8 \%$; OR 3.47 , 95\% CI 1.93-6.35, $\mathrm{p}<0.001)$ were more common in the TOT procedure. ${ }^{21}$ However, when the persistent pain was defined as the pain reported seven days after the procedure, no differences were observed between the techniques $(2.2 \%$ [TVT] vs. $1.9 \%$ [TOT]).

In this study, we aimed to show the proper surgical steps of mid-urethral sling operations while inserting the TOT (Figure 2) and TVT (Figure 3) needles with a pictorial demonstration and discussion of pertinent anatomical landmarks. Despite the higher risk of neural damage during TOT surgery, while inserting the TOT needle staying closer to the ischiopubic ramus will decrease the risk of obturator nerve injury. On the other hand, during TVT surgery the surgeon should insert the needle in close proximity to the posterior part of pubic bone in a longitudinal axis, this will decrease the rate of complications. This model focuses on showing a unilateral insertion of the needle. After bilateral performance of this insertion, the mesh is placed just under the mid-urethra (Figure 4).

\section{CONCLUSION}

Performing the TOT and TVT needle insertions properly with correct hand movements and anatomical knowledge of neighbouring structures will decrease the risk of complications.

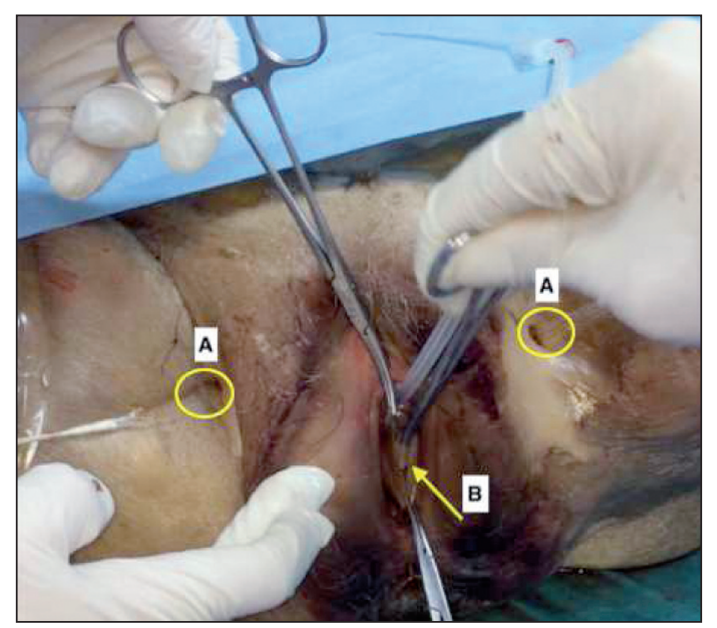

FIGURE 4: Mesh placement under the mid-urethra; A) Mesh exit points on the genitofemoral folds bilaterally, B) Mesh under the mid-urethra (Transobturator tape surgery). 


\section{Acknowledgement}

This study is very important in the learning point of the surgical technique of transobturator and transvaginal sling procedures. These cadavers were imported from science-care organization, U.S.A. for educational purposes.

\section{Source of Finance}

During this study, no financial or spiritual support was received neither from any pharmaceutical company that has a direct connection with the research subject, nor from a company that provides or produces medical instruments and materials which may negatively affect the evaluation process of this study.

\section{Conflict of Interest}

No conflicts of interest between the authors and / or family members of the scientific and medical committee members or members of the potential conflicts of interest, counseling, expertise, working conditions, share holding and similar situations in any firm.

\section{Authorship Contributions}

Idea/Concept: İlker Selçuk; Control/Supervision: Emre Huri; Data Collection and/or Processing: İlker Selçuk, İlkan Tatar; Writing the Article: Illker Selçuk, İlkan Tatar, Emre Huri.

\section{REFERENCES}

1. Norton $P, B$ rubaker $L$. Urinary incontinence in women. Lancet. 2006;367(9504):57-67. [Crossref]

2. Williams ER, Klutke CG. Stress urinary incontinence: the evolution of the sling. Expert Rev Med Devices. 2008;5(4):507-23. [Crossref] [PubMed]

3. Arici B, Pulatoğlu C, Temizkan O, Dogan O, Asicioglu O, Abike F. The effects of outsidein versus inside-out transobturator tapes, for stress urinary incontinence, on sexual function and quality of life: a prospective study. JCOG. 2018;28(2):52-9. [Crossref]

4. Labrie J, Lagro-Janssen AL, Fischer K, Berghmans LC, van der Vaart $\mathrm{CH}$. Predicting who will undergo surgery after physiotherapy for female stress urinary incontinence. Int Urogynecol J. 2015;26(3):329-34. [Crossref] [PubMed]

5. Anger JT, Weinberg AE, Albo ME, Smith AL, $\mathrm{Kim} \mathrm{JH}$, Rodriguez LV, et al. Trends in surgical management of stress urinary incontinence among female Medicare beneficiaries. Urology. 2009;74(2):283-7. [Crossref] [PubMed] [PMC]

6. Richter HE, Albo ME, Zyczynski HM, Kenton $K$, Norton PA, Sirls LT, et al. Retropubic versus transobturator midurethral slings for stress incontinence. N Engl J Med. 2010;362(22): 2066-76. [Crossref] [PubMed] [PMC]

7. Ford AA, Rogerson L, Cody JD, Aluko P, Ogah JA. Mid-urethral sling operations for stress urinary incontinence in women. Cochrane Database Syst Rev. 2017;7: CD006375. [Crossref]
8. Siccardi MA, Valle C. Anatomy, Bony Pelvis and Lower Limb, Pelvic Fascia. StatPearls. Treasure Island (FL); 2019.

9. Delancey JL. True pelvis, pelvic floor and perineum. In: Standring S, ed. Gray's Anatomy: the Anatomical Basis of Clinical Practice. $41^{\text {st }}$ ed. New York: Elsevier; 2016. p.1221-37.

10. Whiteside JL, Walters MD. Anatomy of the obturator region: relations to a trans-obturator sling. Int Urogynecol J Pelvic Floor Dysfunct. 2004;15(4):223-6. [PubMed]

11. Spinosa JP, Dubuis PY, Riederer B. [Transobturator surgery for female urinary continence: from outside to inside or from inside to outside: a comparative anatomic study]. Prog Urol. 2005;15(4):700-6. [PubMed]

12. Hinoul $P$, Vanormelingen $L$, Roovers $J P$, de Jonge $E$, Smajda $S$. Anatomical variability in the trajectory of the inside-out transobturator vaginal tape technique (TVT-O). Int Urogynecol J Pelvic Floor Dysfunct. 2007;18(10): 1201-6. [Crossref] [PubMed]

13. Bonnet $\mathrm{P}$, Waltregny $\mathrm{D}$, Reul $\mathrm{O}$, de Leval J. Transobturator vaginal tape inside out for the surgical treatment of female stress urinary incontinence: anatomical considerations. J Urol. 2005;173(4):1223-8. [Crossref] [PubMed]

14. Huri E, Ezer M, Aydoğan B, Tatar I, Sargon MF. Anatomic transobturator tape (TOT) technique: clinical anatomic landmarks of obturator foramen on female cadavers. Anatomy. 2015;9(1):38-41. [Crossref]

15. Karram MM. Synthetic midurethral slings for the correction of stress incontinence. In: Baggis MS, Karram MM, eds. Atlas of Pelvic
Anatomy and Gynecologic Surgery. $4^{\text {th }}$ ed. Philadelphia, PA: Elsevier; 2015. p.58.9.

16. Jaburek L, Jaburkova J, Lubusky M, Prochazka M. Risk of haemorrhagic complications of retropubic surgery in females: anatomic remarks. Biomed Pap Med Fac Univ Palacky Olomouc Czech Repub. 2011;155(1):75-7. [Crossref] [PubMed]

17. Selçuk I, Tatar I, Fırat A, Huri E, Güngör T. Is corona mortis a historical myth? A perspective from a gynecologic oncologist. J Turk Ger Gynecol Assoc. 2018;19(3):171-2. [Crossref] [PubMed] [PMC]

18. Cox A, Herschorn S, Lee L. Surgical management of female SUI: is there a gold standard? Nat Rev Urol. 2013;10(2):78-89. [Crossref] [PubMed]

19. Keltie K, Elneil S, Monga A, Patrick H, Powell $\mathrm{J}$, Campbell B, et al. Complications following vaginal mesh procedures for stress urinary incontinence: an 8 year study of 92,246 women. Sci Rep. 2017;7(1):12015. [Crossref] [PubMed] [PMC]

20. Biardeau X, Zanaty M, Aoun F, Benbouzid S, Peyronnet B. [Approach and complications associated with suburethral synthetic slings in women: systematic review and meta-analysis]. Prog Urol. 2016;26(4):254-69. [Crossref] [PubMed]

21. Tommaselli GA, Di Carlo C, Formisano C, Fabozzi A, Nappi C. Medium-term and long-term outcomes following placement of midurethral slings for stress urinary incontinence: a systematic review and metaanalysis. Int Urogynecol J. 2015;26(9):1253-68. [Crossref] [PubMed] 